Beamish, D. \& travassos, J.M., 1993. Magnetotelluric studies from two contrasting Brazilian basins: a reassessment of old data.

Physics of the Earth and Planetary Interiors, 81, 261-276.

doi:10.1016/0031-9201(93)90135-V

\title{
Magnetotelluric studies from two contrasting Brazilian basins: a reassessment of old data
}

\author{
D. Beamish ${ }^{*, a}$, J.M. Travassos ${ }^{b, 1}$ \\ ${ }^{a}$ British Geological Survey, Keyworth, Nottingham NG12 5GG, UK \\ ${ }^{b}$ Departmento de Geophysica, CNPq-Observatório Nacional, R. Gen. Bruce 586, 20291 Rio de Janeiro, Brazil
}

\begin{abstract}
Before the mid-1980s large numbers of magnetotelluric (MT) data were collected and interpreted without addressing the possible effects of near-surface (e.g. static) distortion contributions. In the intervening time, modelling and interpretation techniques have improved. There are many instances where extensive, processed tensor survey data of reasonable quality exist on various back-up media. Before any complete reanalysis of these often large data sets, it is useful to investigate the degree of the distortion effects and the approximate degree of resolution of the data. Such assessment should help to clarify whether a full tensorial reanalysis is worth while. The present study provides contrasting examples of the reappraisal of old data sets collected in two Brazilian basins, both with associated seismic reflection profiles and deep exploration well-logs. Both examples use 'simplified' data consisting of only the off-diagonal tensor elements. These data are used in a limited way to assess static distortion and their intrinsic resolution capabilities. In the first example, from the basalt-covered Paraná basin, a very high degree of static distortion is displayed. The application of simple distortion correction techniques allow the data to define the main (vertical) geoelectric units of the basin. In the second example, from the Solimôes basin in northern Brazil, static distortion, although less severe, can be readily identified. In this complex petroleum province the resolution of structure, both vertical and lateral, is of very low order. The MT data appear 'blind' to the detail of the Palaeozoic sedimentary rocks, and more detailed reanalysis is probably not warranted.
\end{abstract}

\section{Introduction}

Throughout the 1970s and early 1980s, large numbers of magnetotelluric (MT) data sets were collected in various studies world-wide. Most of these data were collected and interpreted without provision for the possible effects of near-surface (e.g. static) distortion contributions. Since the time of the data collection, our understanding and ability to deal with such effects, and our modelling and interpretation techniques, have

* Corresponding author. Telephone: 0602363 432. Fax: 0602 363 145. EMAIL: $k_{-}$dbe@vaxa.nerc-keyworth.ac.uk.

1 Also at: PETROBRAS/CENPES/SEGEF, 21910 Rio de Janeiro, Brazil. improved. The present study is a reappraisal of two data sets from the 1980 s collected in two very different Brazilian basins.

Although the use of MT studies in whole crustal and gross (regional) basin evaluation is well documented, studies concerning more detailed (e.g. stratigraphic) evaluations, of more direct potential value to the exploration industry, are limited. Here we consider hydrocarbon exploration data from two contrasting Brazilian basins, both with associated seismic reflection profiles and deep resistivity well-logs. In the first case, the Paraná basin, massive flood basalts cover the sedimentary section; in the second, the Solimôes basin, upper Palaeozoic sediments are intruded by a succession of major diabase sills. The two basins provide contrasting examples of the intrin- 
sic resolution of the MT wavefield. In the first case, vertical resolution is adequate to define the configuration of the basin; in the second case, resolution is much less satisfactory.

Both analyses use 'old' commercial data consisting of only the off-diagonal elements ( $\rho_{x y}$, $\phi_{x y} ; \rho_{y x}, \phi_{y x}$ ). Throughout this study, $x y$ is used to denote a geographical north-south measurement and $y x$ is used to denote a geographical east-west measurement. Using such data we cannot apply formal tensor rotation/decomposition techniques to determine fully the $2 \mathrm{D}$ and/or $3 \mathrm{D}$ contributions to the response set. The data are therefore used in a limited way to assess both their attributes and capabilities within the two exploration contexts. We are fully aware that more modern surveys would provide better data together with a greater control of near-surface static contributions, and would therefore offer more rigorous interpretation capabilities. Our main purpose here is to re-examine the data, using newer procedures, with a view to understanding the benefits and shortcomings of MT when applied to such difficult basin environments. In broad terms, the data limitations are not severe in the case of the Paraná basin and an adequate interpretation has been produced. The limitations in the case of the data from the Solimôes basin prove to be far more restrictive.

\section{Paraná basin: background}

MT data were acquired by commercial contractors in a number of study areas within the basin in the early 1980s (e.g. Stanley et al., 1985). Most of the basin, some $800000 \mathrm{~km}^{2}$, is covered with basalts up to $2 \mathrm{~km}$ thick (Fig. 1a), which overlie a series of Palaeozoic sediments containing known hydrocarbon source and reservoir rocks (Milani et al., 1990). Stanley et al. (1985) discussed regional MT surveys (average site separation of $12 \mathrm{~km}$ ) conducted further north in the region of a major linear uplift (the Ponta Grossa arch). Such regional-scale MT is particularly useful when developing a crustal-scale model for the general configuration of rock units across zones which have been subjected to tectonic modification.

The data discussed here come from an 84-site grid survey undertaken in the Clevelandia area of the basin (Fig. 1a). The data were acquired in late 1981. An exploration well, 2-AL-1-SC, is shown in relation to the survey sites in Fig. $1 b$. The average site separation across the grid is some $2 \mathrm{~km}$. This site separation is about $500 \mathrm{~m}$ less than the depth to the most conductive sedimentary sequences (see below). The grid survey was therefore intended to provide a detailed $3 \mathrm{D}$ appraisal of the configuration of the sedimentary units away from the control provided by the exploration well.

The deep induction $\log$ is shown in Fig. 2, alongside two resistivity-depth models that will be discussed below. Formation stratigraphy is indicated by the horizontal dashed lines. The base of the Serra Geral flood basalts (unit a, Fig. 2) is the first marker at $1230 \mathrm{~m}$, and beneath this unconformity a sequence of conductive marine and continental Palaeozoic sedimentary units (Units b-i inclusive, Fig. 2) occurs (Milani et al., 1990). In terms of basin-wide hydrocarbon potential, the Permian shale sequence within the Irati formation (Unit $f$ ) is considered to be a possible source rock. In the case of 2-AL-1-SC, the formation is intruded by a thin sill (about $25 \mathrm{~m}$ in thickness) whose thermal impact will have influenced hydrocarbon maturation. The well encounters Silurian sediments (Furnas formation, Unit $j$ ) at $3377 \mathrm{~m}$ and enters metagabbroic basement at $3850 \mathrm{~m}$.

The induction log of Fig. 2 provides a good example of the wavenumber content of many of the induction logs from the basin. The largest variations occur at the metre scale and relate to thin-bed lithology (including here intrusives) rather than formation stratigraphy per se. The only substantial transition in vertically averaged resistivity occurs between the flood basalts and the underlying sediments. The seismic sections from the Clevelandia survey are of poor quality and have not been interpreted. The sections indicate predominantly flat-lying horizons but can provide little convincing control for MT interpretation. 

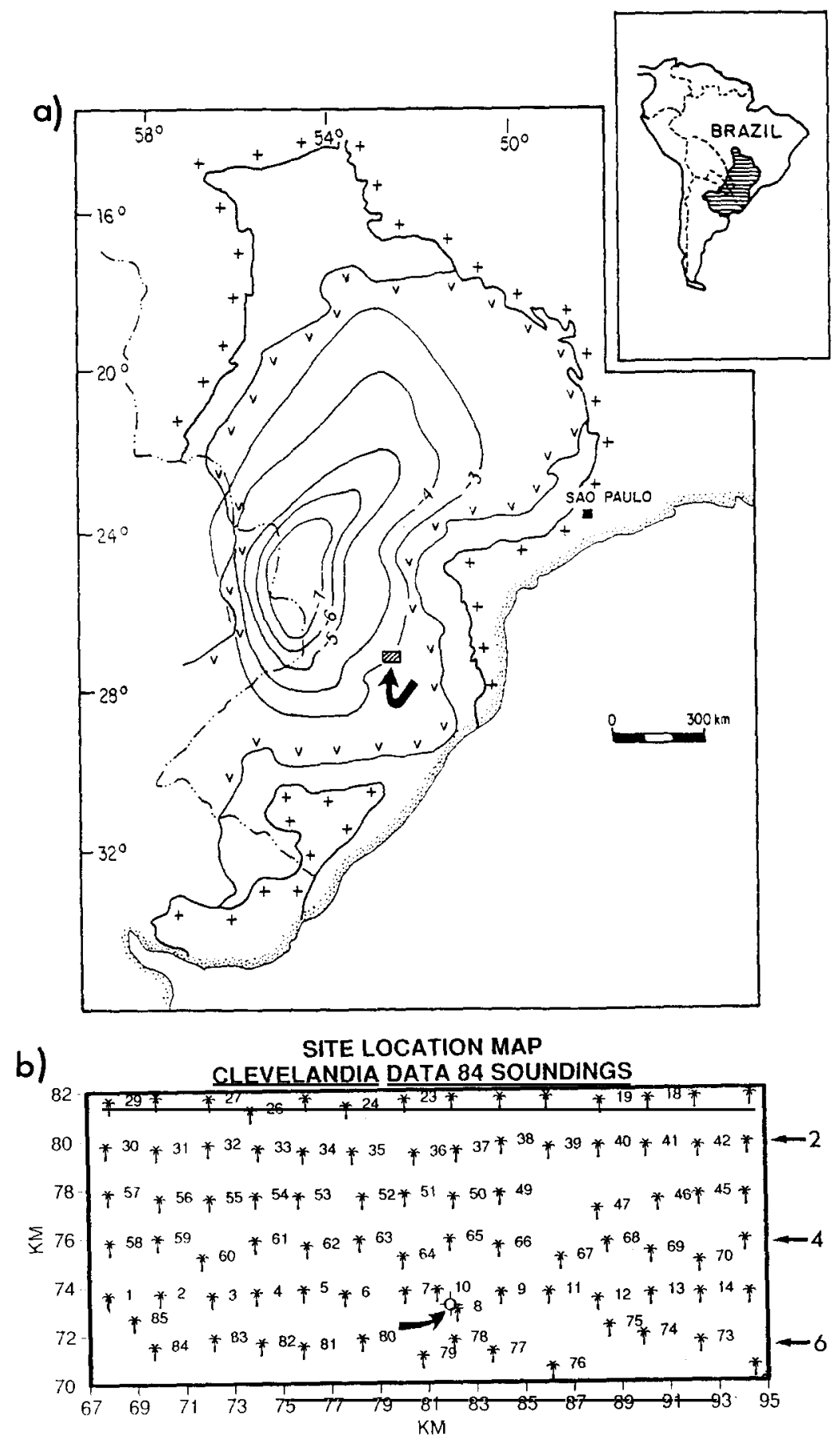

Fig. 1. Survey location, Paraná basin. In the upper figure (a) the inset shows the location of the Paraná basin on a map of South America. The main map shows the extent of basalt cover (' $v$ ' symbols) and structural contours of depth to seismic basement (contour interval $1 \mathrm{~km}$ ), after Milani et al. (1990). +, Basin margins, in Brazil. Position of Clevelandia array is shown arrowed (not to scale). The lower figure (b) shows MT sounding locations, and Well 2-AL-1-SC is arrowed. Three east-west profiles $(2,4$ and 6$)$ are arrowed. 


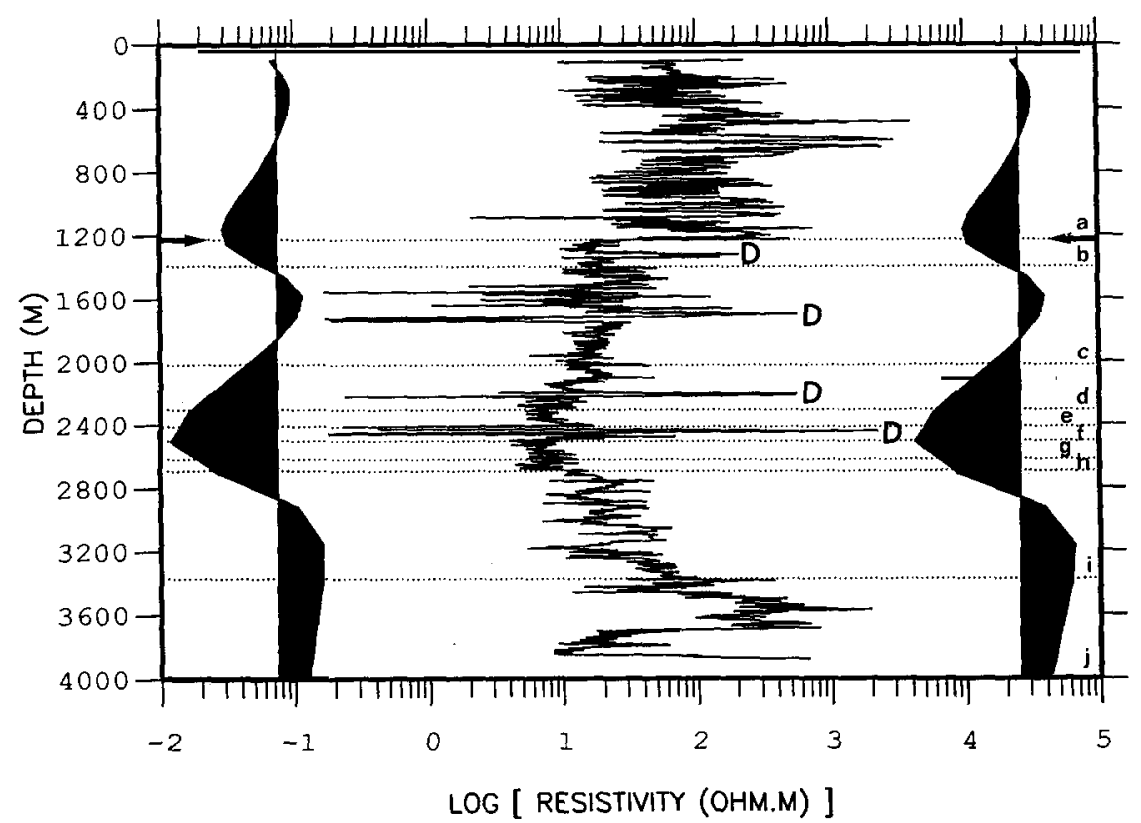

Fig. 2. Induction $\log (1 \mathrm{~m}$ sampling) and stratigraphy (dotted lines) from Well 2-AL-1-SC. Base of Serra Geral basalt (unit a) is arrowed. D, Diabase sills. Infilled profiles are the reflectivity coefficient series (Beamish and Travassos, 1992c) from the smooth inversion models at Sites 8 (left) and 10 (right). The same arbitrary gain factors were applied to both. Formations: a, Serra Geral basalt; b, Botucato; c, Rio de Rasto; d, Terezina; e, Serra Alta; f, Irati; g, Palermo; h, Rio Bonito; i, Itararé; j, Furnas Formation.

\section{Paraná basin: data characteristics}

The data acquired by the Clevelandia survey have been presented and discussed by Beamish and Travassos (1992a, b). Those studies demonstrated that static distortion, producing parallel offsets, is a significant feature of all the sounding data collected in this basalt-covered environment. No additional survey information was collected with regard to the control of statics, and a number of correction schemes, as applied to this survey, have been discussed by Beamish and Travassos (1992b). The preferred method involves a combination of spatial averaging and a parametric constraint (a uniform resistivity of the basalt 'layer'), together with phase-only data inversion. These procedures provide estimates of the frequency-independent gain factors for both components, which are then used to correct the measured apparent resistivity data. The result of applying these procedures are the 'static-corrected' sounding data in the $x y$ and $y x$ components.
A high degree of spatial consistency is observed in the phase of the off-diagonal components. Beamish and Travassos (1992b) suggested that a realistic conceptual model consists of a 3D thin sheet over an Earth in which the layer parameters vary sufficiently slowly (laterally) that a 1D interpretation of the static corrected data is valid down to a certain minimum frequency (about $0.1 \mathrm{~Hz}$ ). This form of conceptual model has been discussed previously by Jones (1988) for MT data acquired across a sedimentary basin. At frequencies between 0.1 and $0.01 \mathrm{~Hz}$, where departures from the conceptual model become significant, effective penetrations range from 2000 to $5000 \mathrm{~m}$. This suggests that the $1 \mathrm{D}$ assumption will only introduce significant errors in terms of basement structure.

\section{Paraná basin: data modelling}

In terms of basin stratigraphy, it is important to establish the 'correct' number of layers when 
1D layered modelling is used for interpretation. In the case of the Clevelandia data, all the soundings can be adequately represented by a four-layer model (Beamish and Travassos, 1992b). The data resolve three main units above the electrical basement. The upper (resistive) unit corresponds to the flood basalts, and the entire Palaeozoic sedimentary sequence is then represented by two layers, the lower of which is a highly conducting (about $1 \Omega \mathrm{m}$ ) formation. The underlying (resistive) half-space, at a depth of about $3 \mathrm{~km}$, conforms to the electrical, seismic (e.g. Fig. 1a) and geological (e.g. Fig. 2) basement.

It is now accepted that smooth, minimumstructure models offer a number of advantages over conventional, layered-model construction schemes (Oldenburg, 1990). In smooth model construction, the number of interfaces need not
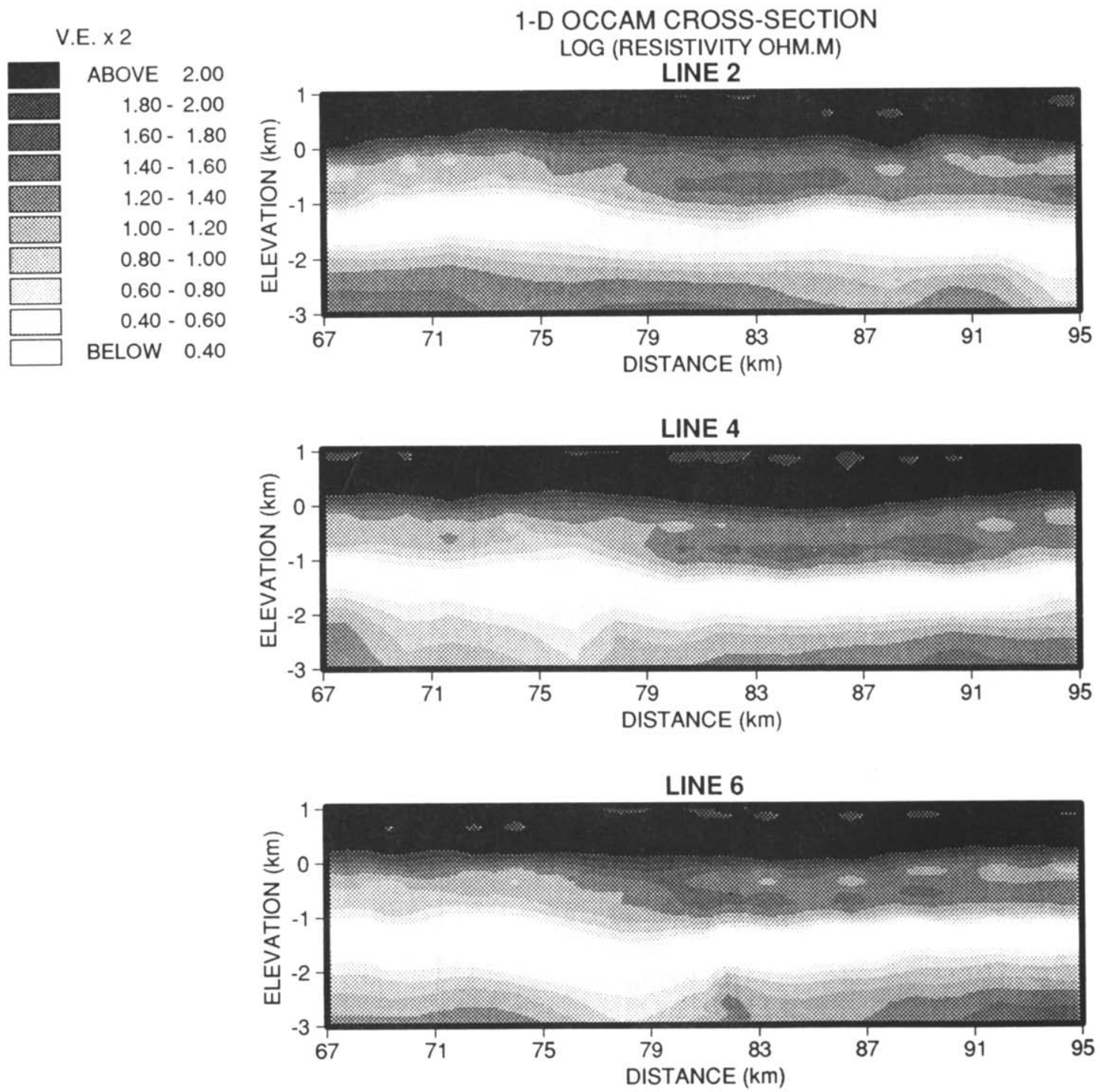

Fig. 3. Three resistivity cross-sections from east-west lines 2, 4 and 6 (Fig. 1). Cross-sections assembled from the results of 1D smooth inversions. Data used were the Berdichevsky invariant formed from the off-diagonal soundings which had been corrected for static distortion. Logarithmic resistivity scale and linear depth. Vertical exaggeration: $\times 2$. 


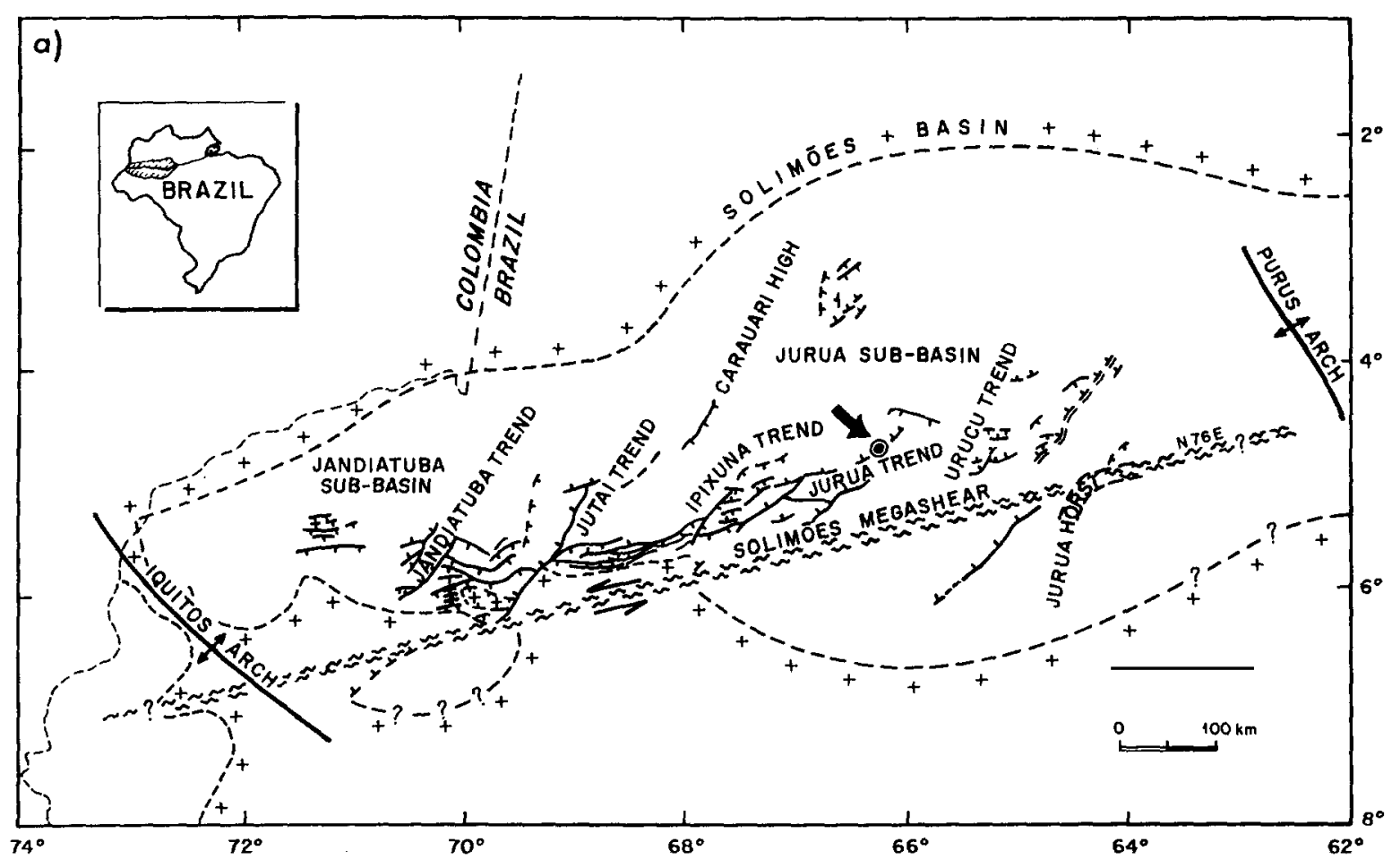

Fig. 4. Survey location, Solimôes basin. Diagram (a) shows main sub-basins within the Solimôes basin (Brazil, 1990). The location of the MT survey within the Jurua sub-basin is shown arrowed. Diagram (b) shows Profiles 50-RL-137, 50-RL-138 and 50-RL-139, with both MT measurements and seismic reflection data. Locations of Wells 1-JR-1AM, 3-JR-4AM and 3-JI-4AM are also shown.

be predefined, and the resulting models appear more stable and less susceptible to parameter equivalencing when cross-sections are constructed. 1D smooth OCCAM inversion (Constable et al., 1987) was applied to the Berdichevsky invariant data (formed from the two static corrected components) and solutions were obtained at an r.m.s. misfit of 1.3 for all soundings. The smooth models incorporate 30 layers per decade of depth.

Resistivity cross-sections, obtained by assembling the smooth inversion models, across three east-west profiles, each containing 14 soundings, are shown in Fig. 3. With reference to Fig. 1b, Line 2 uses the data from Sites 30-43, Line 4 uses the data from Sites 58-71 and Line 6 uses the data from Sites $72-85$. We emphasise that the results in Fig. 3 are property cross-sections, and structural (e.g. stratigraphic) horizons can only be inferred using well-log control. The resistive basalt cover is clearly of highly uniform thickness across the mapped area of Fig. $3(28 \mathrm{~km} \times 10 \mathrm{~km})$. The upper sedimentary unit displays an east-west variation in resistivity that is spatially consistent across the three profiles. The minimum resistivities which can only be associated with a series of formations (see below) are mapped as primarily a horizontal unit in the east but with implied subhorizontal components of dip at eastings less than $81 \mathrm{~km}$. Any 'structure' at basement depths (elevations less than $-2 \mathrm{~km}$ ) implied by the resistivity variations must be treated with caution because of the limitations of the present 1D assessment.

\section{Paraná basin: well-log control}

Resistivity cross-sections such as those of Fig. 3 , whether the result of $1 \mathrm{D}$ or $2 \mathrm{D}$ modelling, are an attempt to image resistivity and depth simultaneously. For stratigraphic mapping purposes we 


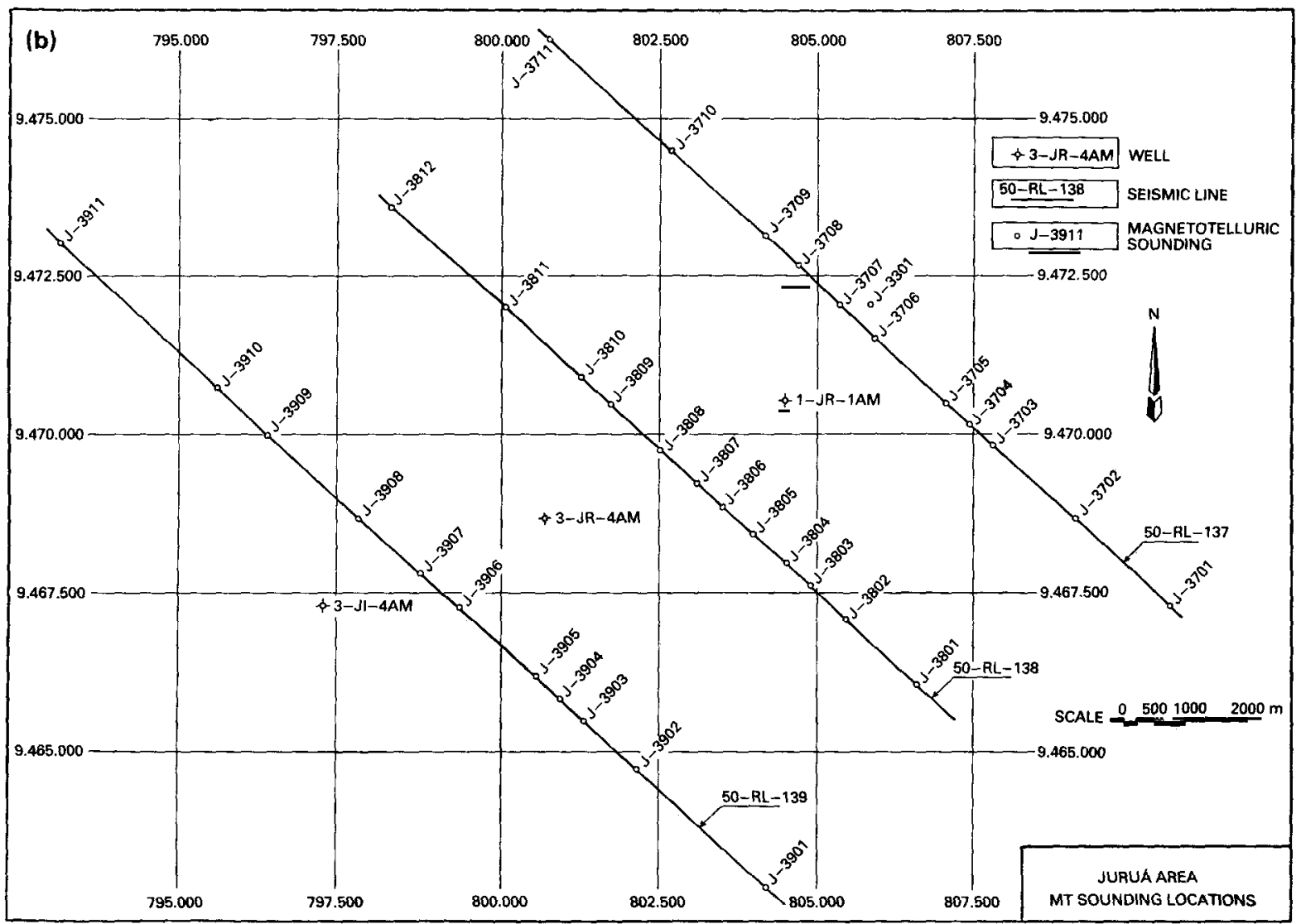

Fig. 4 (continued).

have found it useful to derive a set of primarily depth-dependent 'markers' which can be tied to the control provided by a well-log. Beamish and Travassos (1992a, c) discussed the use of the pseudo-reflectivity transformation which can be used to process any available resistivity-depth profile. When applied to the results of smooth, regularised inversion procedures, the transform operates on a 'stable' profile containing only low wavenumber components.

The reflection coefficients, determined from the smooth OCCAM models at Sites 8 and 10 adjacent to 2-AL-1-SC, are shown in Fig. 2 alongside the induction log and stratigraphic horizons. It should be noted that the OCCAM resistivity models and hence the reflection coefficient series are sampled on a logarithmic depth scale, whereas the induction $\log$ scale is linear. The markers offered by the reflection coefficients consist of positive and negative excursions together with zero crossings. Negative values here indicate transitions to more conductive sequences. In Fig. 2 the first maximum in the negative set is clearly associated with the base of the basalt (arrowed) whereas the deeper negative maximum is associated with the depth of the minimum resistivities found in the induction log. These low resistivities are, in turn, associated with conductive sand, siltstones and shales of the Irati, Palermo and Rio Bonito formations (Units $f, g$ and $h$, respectively, Fig. 2). Fortuitously, the precise negative maximum occurs on a stratigraphic horizon sepa- 
rating the Irati and Palermo formations. The transition to resistive basement is indicated by the final transition to positive values.

The use of reflection coefficients for cross-sectional mapping was discussed further by Beamish and Travassos (1992c), where further interpretation of the Clevelandia data can also be found. Inspection of the induction logs from a number of distributed exploration wells also indicates that the bulk features of the resistivity profile of Fig. 2 are repeated in many areas. The reflection coefficients shown in Fig. 2 therefore probably represent the maximum achievable vertical resolution across major parts of this extensive area, in which exploration is still continuing.

\section{Solimôes basin: background}

Modern hydrocarbon exploration activities in the Palaeozoic Solimôes basin in the NW of Brazil (Fig. 4a) have been undertaken in two separate phases. The first campaign (late $1950 \mathrm{~s}$ and early 1960s), which involved 16 stratigraphic wells, revealed an extremely attractive basin with hydro- carbon potential. The second (seismic-based) campaign, launched in 1975 , culminated with the discovery in 1978 of commercial quantities of gas in the Juruá Trend, and further evolution of research activities led to the discovery in 1986 of oil in the Urucu Trend (Brazil, 1990).

Located in the central part of the basin, the Juruá province is associated with the Juruá structural lineament, a tectonic feature composed of asymmetrical anticlines associated with reverse faults. In 1982, MT data were acquired along three profiles with associated seismic reflection data (Fig. 4b). The data considered are again only the off-diagonal elements of the soundings in the geographic north-south $(x y)$ and east-west $(y x)$ components. The survey area, with an almost uniform elevation of about $80 \mathrm{~m}$, contains three exploration wells (3-JI-4AM, 3-JR-4AM and 1JR-1AM), as shown in Fig. 4b. The induction logs from two of the wells are shown in Fig. 5 alongside the stratigraphic column. It can be seen that the induction logs from the two wells are almost identical. Highly conductive Tertiary (Solimôes formation) and Cretaceous (Alto do Chão formation) fluvial sediments cover the Palaeozoic se-

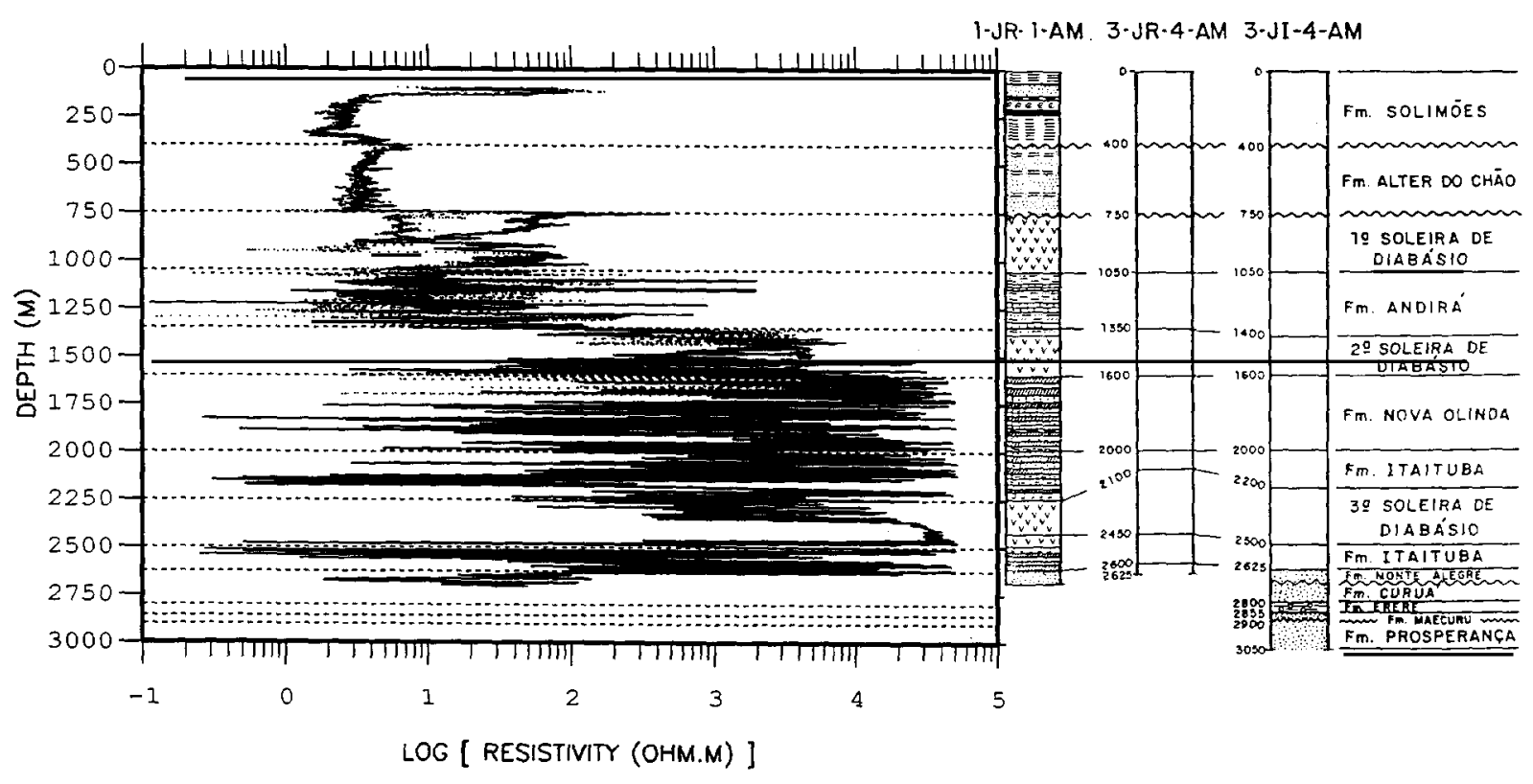

Fig. 5. Induction logs from Wells 3-JR-4AM (line) and 3-JI-4AM (dotted) together with stratigraphic sequence (horizontal dashed lines). Stratigraphic data from all three exploration wells are shown on the right. 
quence, providing a cover thickness of $750 \mathrm{~m}$. The sediments are intruded by three massive diabase sills above Devonian marine shales (Prosperança formation) which are gas prone. The interpreted seismic section along Profile 50-RL-138 is shown in Fig. 6, and indicates a high-angle reverse fault overhanging an anticlinal basement structure. The direction of the three profiles (N42 W; Fig. 4b) is almost perpendicular to the direction of inverse faulting $\left(\mathrm{N} 30^{\circ} \mathrm{E}\right)$ found in the study area.

\section{Juruá province: data characteristics}

Sounding data in both components along Profile 50-RL-137 are shown in cross-sectional form in Fig. 7. (The data along the other two profiles are similar in form.) The data displayed in this figure are smoothed versions of the original sounding data and each sounding is 'tied' at the highest frequency $(100 \mathrm{~Hz})$ to the site location. Curves are scaled identically across the profile but only the relative shapes and magnitudes of the sounding data are displayed. Despite the fact that the profile must traverse a known fault (e.g.
Fig. 6), only subtle variations in response characteristics are observed.

To examine absolute variations, and static offsets, the anisotropy ratios and associated phase differences between the $x y$ and $y x$ components for the 11 sites along Profile 50-RL-139 are shown in Fig. 8. Significant parallel behaviour in apparent resistivity between the two components is observed at all sites down to a frequency of about $0.1 \mathrm{~Hz}$. Across the same bandwidth phase differences are generally less than $12^{\circ}$. Although the actual offsets, as monitored by the anisotropy ratios, amount to absolute values of less than two (in apparent resistivity), they appear to be stable functions of frequency and therefore are significant. In summary, the data characteristics of the Juruá survey appear to require at least a $2 \mathrm{D}$ analysis with allowance for small (of the order of less than two) superimposed static contributions.

\section{Juruá province: vertical resolution}

The main problem for MT resolution in the Juruá province stems from the highly conducting

\section{PROFILE 50-RL-138}

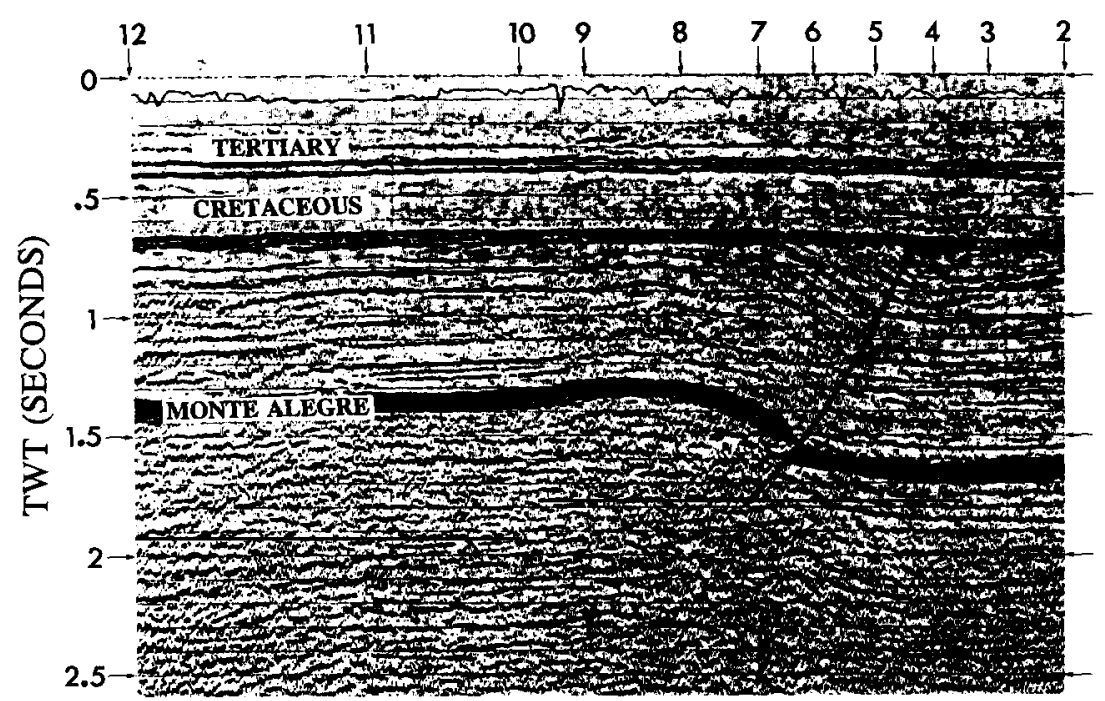

Fig. 6. Interpreted seismic section along Profile 50-RL-138. Numbers $12-2$ denote locations of the MT soundings. Section length is close to $10 \mathrm{~km}$. 

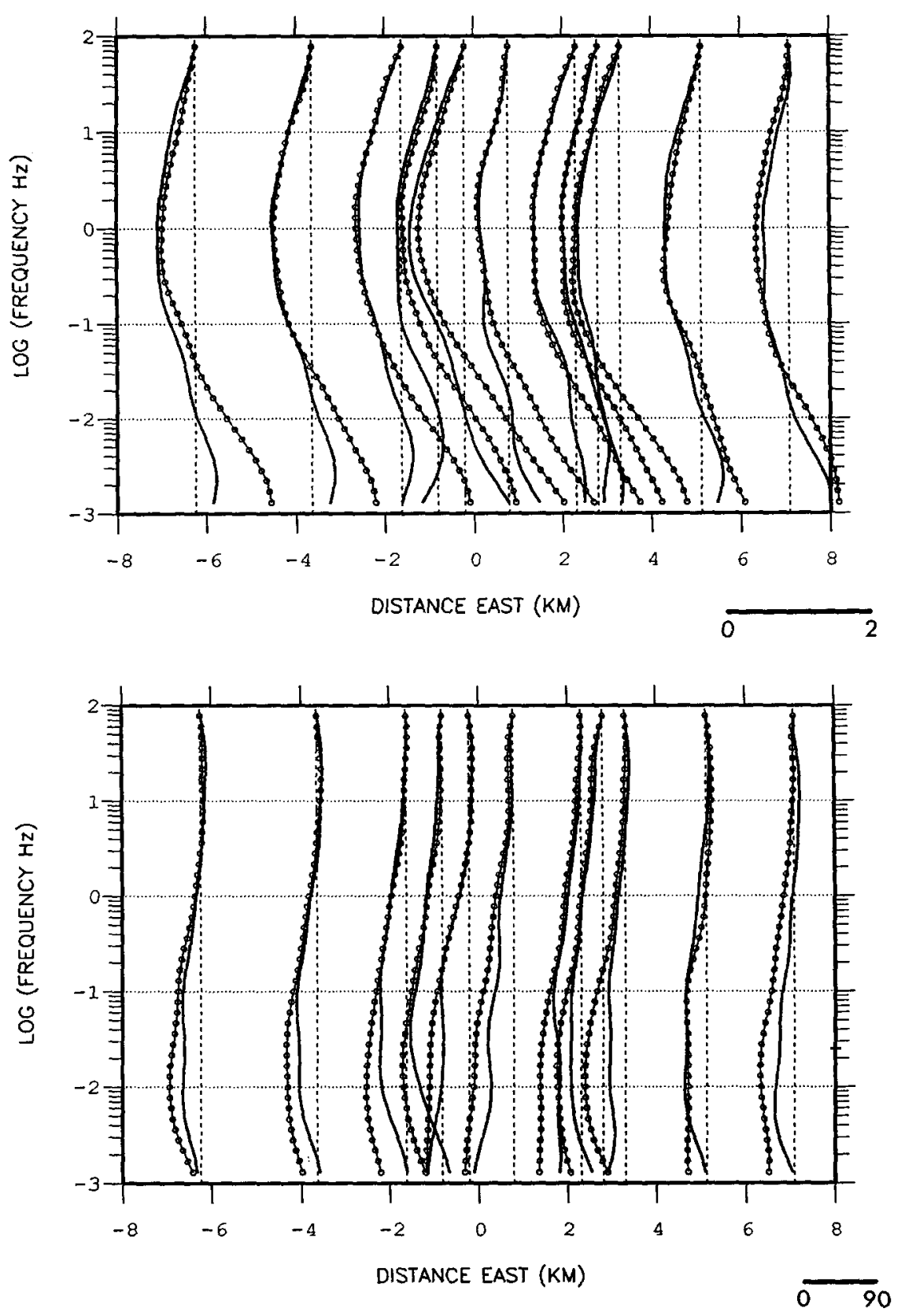

Fig. 7. Example of smoothed sounding data along Profile 50-RL-137. Data are plotted as a function of profile location (vertical dashed lines). Results are 'tied' at $100 \mathrm{~Hz}$ so that only the relative shapes and magnitudes are preserved. Line with symbols is $x y$ component and line only is the $y x$ component. The upper diagram shows apparent resistivity $(\Omega \mathrm{m})$, on a logarithmic scale; the scale bar (bottom right) denotes two decades. The lower diagram shows phase on a linear scale; the scale bar (bottom right) denotes $90^{\circ}$. 
cover coupled with the subsequent increasing resistivity of the deeper sediments and intrusives (Fig. 5). Using the induction log results, the upper two formations provide integrated conductances of $136 \mathrm{~S}$ (Solimôes formation) and $94 \mathrm{~S}$
(Alto do Chão formation). All subsequent stratigraphic units, particularly the resistive diabase sills, give rise to very small conductance values. The complete 'logged' Palaeozoic sequence only contributes a combined conductance equivalent
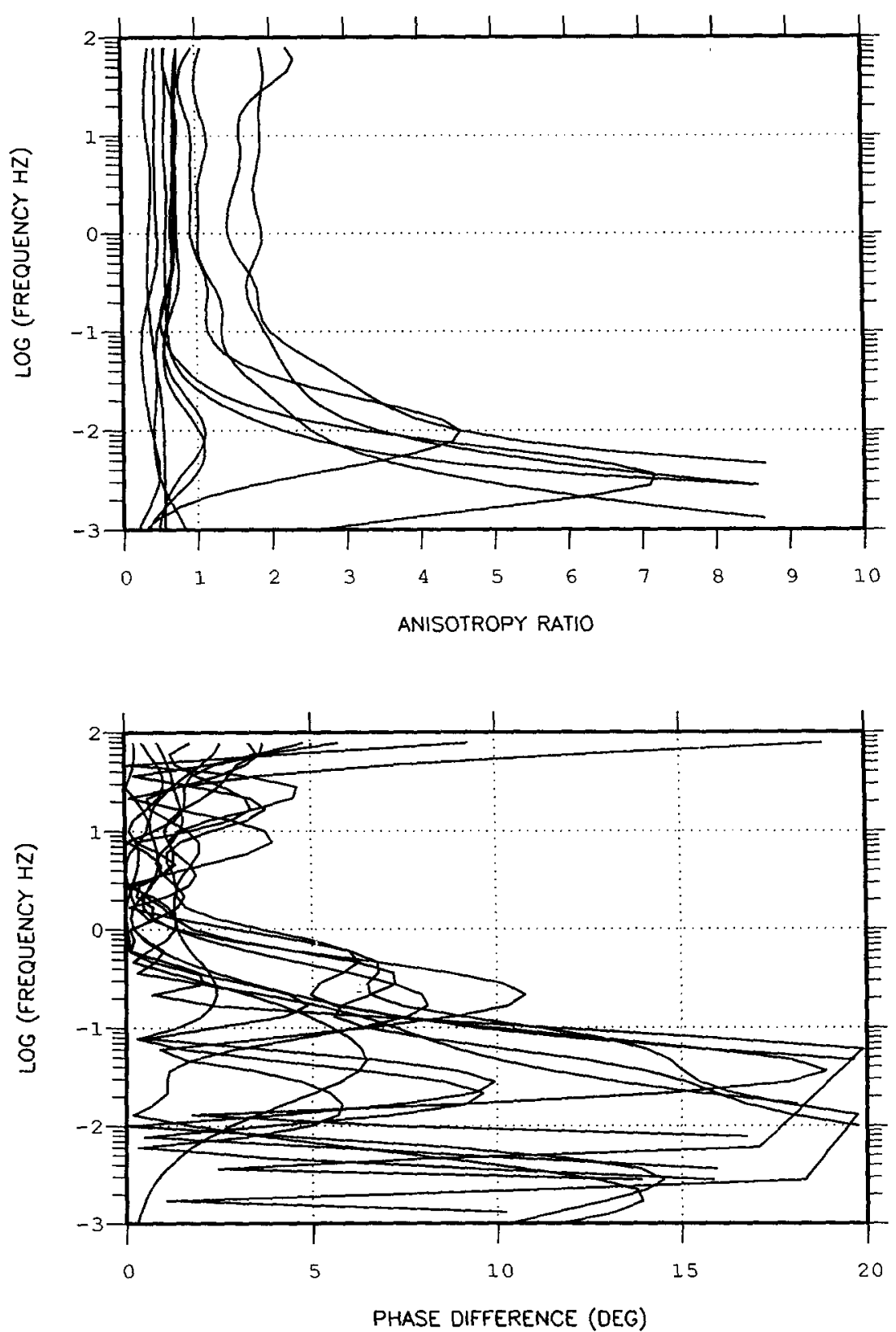

Fig. 8. The upper diagram shows anisotropy ratios $\left(\rho_{y x} / \rho_{x y}\right)$ for the 11 soundings along profile 50-RL-139. The lower diagram shows the corresponding phase differences between the components $\left(\phi_{y x}-\phi_{x y}\right)$. 
to some $15 \%$ of the conductive Tertiary and Cretaceous cover. Thus, despite some of the large resistivity contrasts that exist at depth, the whole Palaeozoic succession remains unresolvable in detail.

We can examine the effective penetration of the data using the real part of the complex $\mathbf{c}$ response (Weidelt, 1972). The real part of $c$ is a scale length which can be understood as an effective penetration. The real and imaginary parts of the $c$ response at Site 3909, which has an anisotropy ratio of order one, are shown in Fig. 9. The first three decades of the data, down to 0.1 $\mathrm{Hz}$, are taken up in penetrating the cover (to a depth of $750 \mathrm{~m}$ ). Across this interval the real part of the $\boldsymbol{c}$ response is a monotonic decreasing function of frequency indicating $1 \mathrm{D}$ behaviour. As the response penetrates the upper diabase sill and subsequent sedimentary section at lower frequencies, additional structural complexity is observed.

\section{Juruá province: 2D modelling}

Despite the very low order vertical resolution, an examination of the lateral influences on the data is warranted. A simplified 2D forward model, based on the induction logs and the seismic section, was constructed and is shown in Fig. 10. The depth of the basement (assumed resistive) was set at $3.5 \mathrm{~km}$ and forms a terminating half-space. The finite-element algorithm of Wannamaker et al. (1987) was used to obtain the transverse electric (TE) and transverse magnetic (TM) mode response data at 11 sites at $1 \mathrm{~km}$ intervals $(-5$ to $+5 \mathrm{~km}$ in Fig. 10). The response data were obtained at 10 uniformly spaced frequencies between 5 and $0.005 \mathrm{~Hz}$. Nominal $5 \%$ errors were assigned to the synthetic data and a $2 \mathrm{D}$ smooth inversion procedure (OCCAM2D, deGrootHedlin and Constable, 1990) was applied to the data.

\section{EFFECTIVE PENETRATIONS (Re C)}
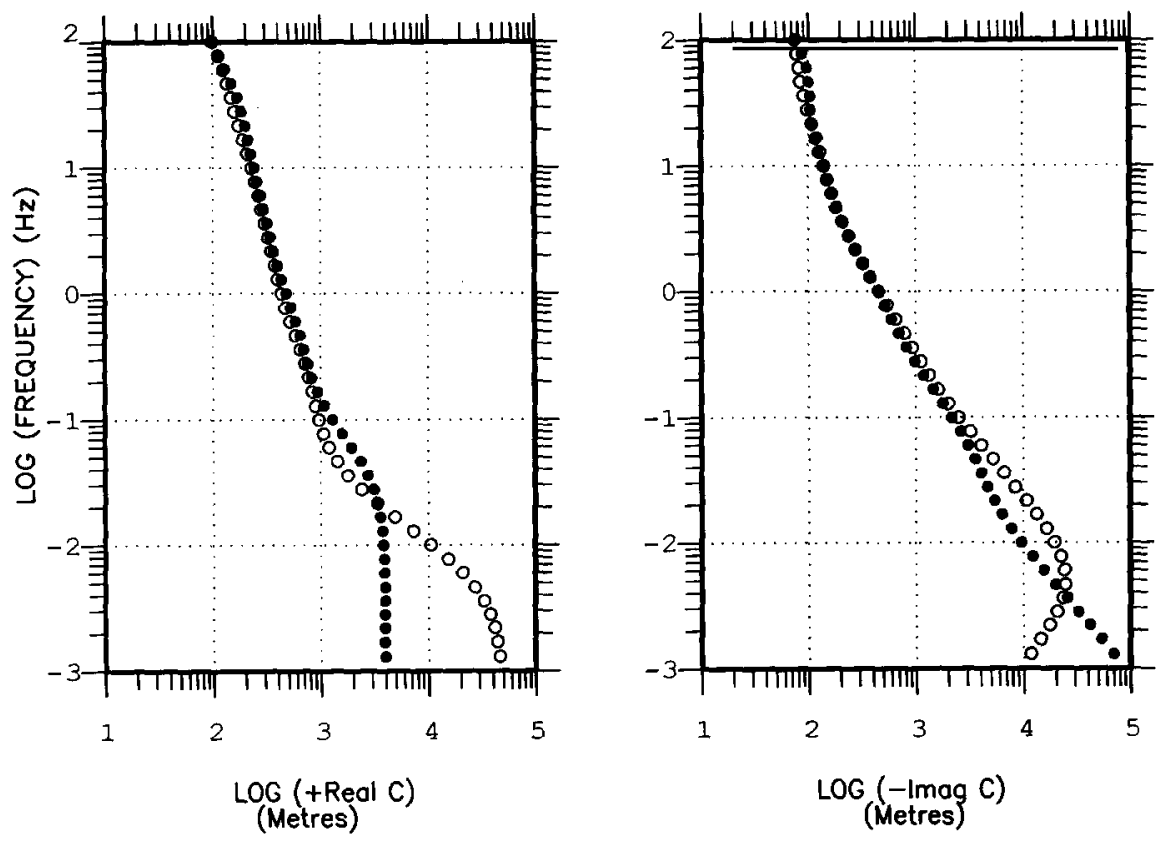

Fig. 9. Example of sounding data from Site 3909 (Profile 50-RL-139), shown as the real and imaginary parts of the complex $c$ response. $\bullet x y$; $O, y x$. 

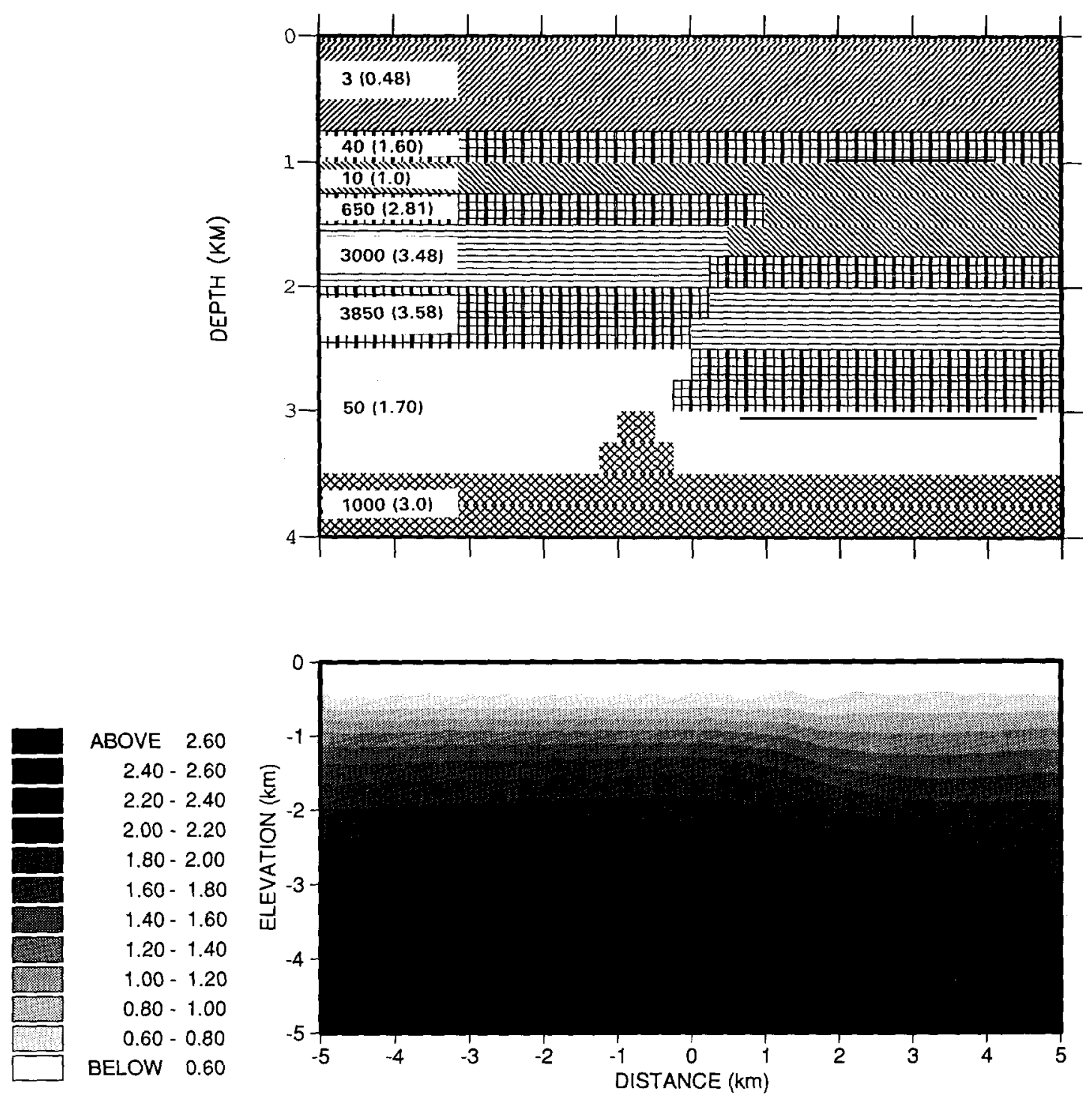

Fig. 10. Upper diagram shows the synthetic resistivity model based on induction log and seismic results which contains a simplified reverse fault above a basement anticline. Resistivities of formations are shown in ohm-metres with logarithmic values in parentheses. The lower diagram shows the resistivity model produced by $2 \mathrm{D}$ smooth inversion of response data calculated using the synthetic model (using both TE and TM modes). Resistivity is shown on a logarithmic scale.

Starting from a half-space of $100 \Omega \mathrm{m}$, the $2 \mathrm{D}$ inversion produced a regularised model with an overall r.m.s misfit of 0.11 with respect to the synthetic data and its nominal $5 \%$ errors. The inversion model is shown beneath the synthetic model in Fig. 10, and represents a 'best possible resolution case' for synthetic data with no noise. For survey data we should only reasonably expect to obtain a fit at an r.m.s. misfit of unity or greater. In such circumstances, the geometrical attitudes within the inversion model would be smoother and would contain lower-order wavenumber components.

The limited vertical resolution found within the inversion model is discussed below. From Fig. 10 it is clear in this 'best-case' study that, al- 

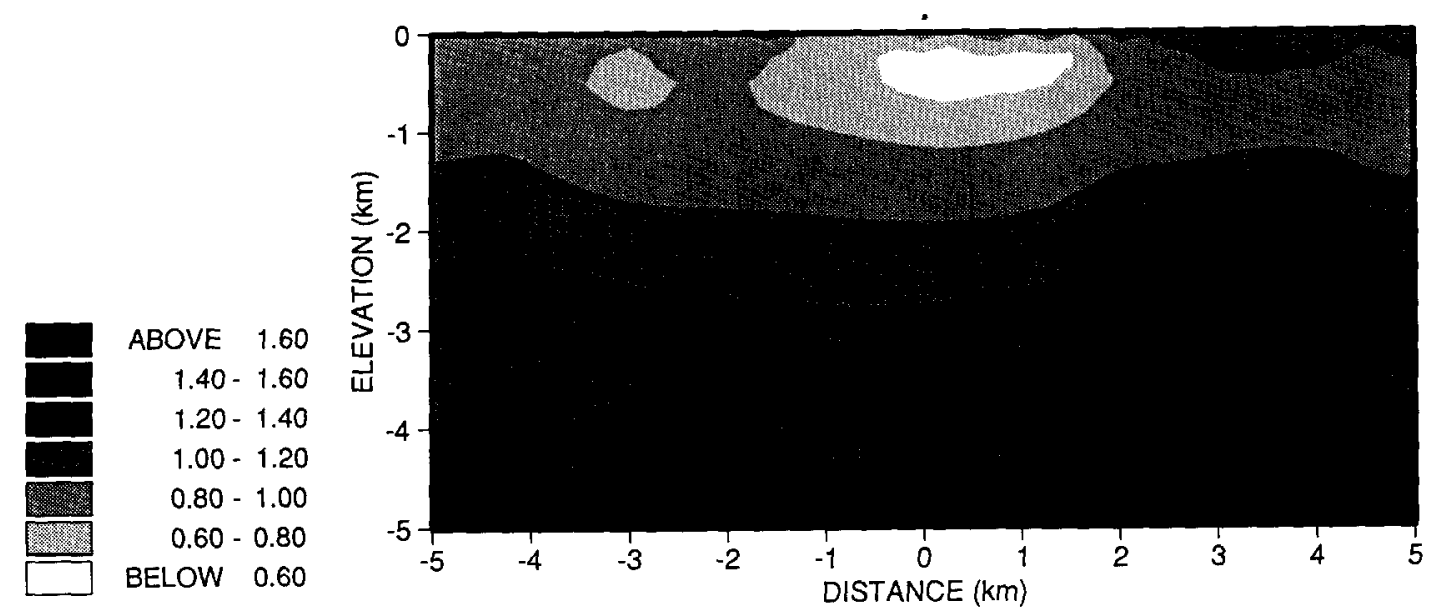

Fig. 11. Resistivity model produced by 2D smooth inversion of response data (the assumed TE and TM modes) along Profile 50-RL-138, translated to a north-south direction. Resistivity is shown on a logarithmic scale.

though lateral effects are detected, they are represented (as expected) only as relatively longwavelength features. Sub-parallel attitudes 'spread' to the upper kilometre of the section where the conductive sedimentary units and up- per diabase sills are flat-lying. The basement anticline appears as an unresolved feature.

A major difficulty when approaching $2 \mathrm{D}$ modelling of the Jurua data is that only the off-diagonal elements were provided and the measure-
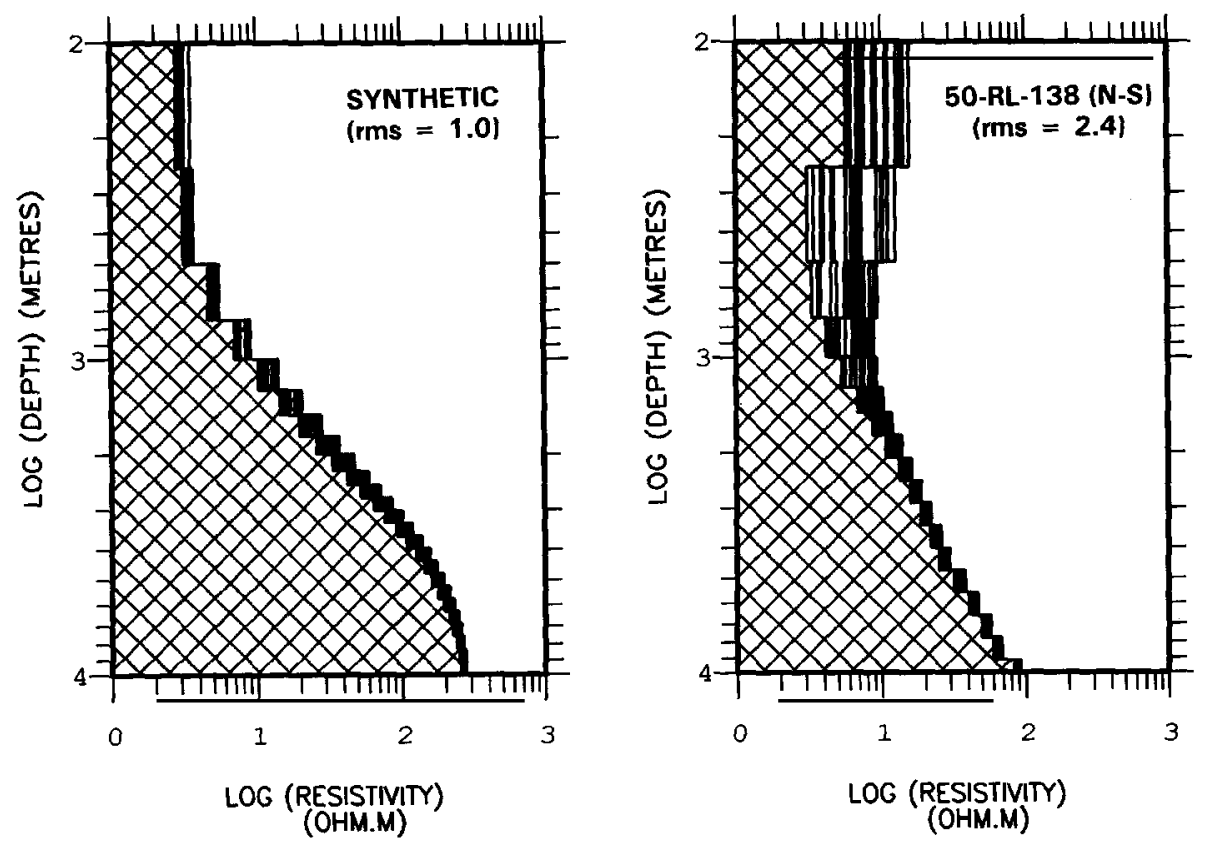

Fig. 12. Vertical resistivity profiles from the results of $2 \mathrm{D}$ smooth inversion. The left-hand diagram shows 23 profiles $(-5$ to +5 $\mathrm{km}$ ) from the inversion of the synthetic model of Fig. 10 with a basement resistivity of $200 \Omega \mathrm{m}$. The right-hand diagram shows 23 profiles $(-5$ to $+5 \mathrm{~km}$ ) from the inversion of the data along Profile 50-RL-138, translated to a north-south direction. 
ment profiles run NW-SE. In such circumstances, it is first necessary to transpose the problem geometrically, to undertake an approximate 2D assessment. Site locations along the three profiles were geometrically translated to a north-south orientation and it was then assumed that the $x y$ component data related to a TM-mode response (along the north-south profile) and the $y x$ component represented a TE-mode response. Treated in this way, the data 'examine' east-west structural contributions to the translated northsouth profile, although the degree of approximation can be seen to be very high. One mitigating feature of the data, in relation to the approximation, is their high degree of lateral continuity (Fig. 7). As the likelihood of obtaining a valid 2D model using these data is so low, our main purpose here is to examine their approximate ' $2 D$ resolution capability'.

The data along each north-south profile were again inverted using the OCCAM2D algorithm but with internal allowance for amplitude adjustments as a result of static shift contributions (deGroot-Hedlin, 1991). Again, 10 uniformly spaced frequencies between 5 and $0.005 \mathrm{~Hz}$ were used. Site spacings along the translated northsouth profiles were inevitably highly irregular. In the case of Profile 50-RL-138, the best-fitting inversion model achieved an overall r.m.s. misfit of 2.4 with respect to the 220 observational data used (11 sites). The model is shown in Fig. 11. The range of resistivities returned is far less than in the case of the synthetic data (Fig. 10). It is clear from Fig. 11 that in terms of lateral resolution, given the level of the approximation, we can only infer smooth flat-lying features with a reasonable degree of lateral continuity. In terms of vertical resolution, however, it is possible to take the comparison a stage further.

It can be seen in Fig. 11 that a relatively conductive basement is implied by the variation of resistivity with depth. A number of synthetic models (Fig. 10) with different values of basement resistivity were inverted. Fig. 12 shows the vertical profiles obtained with a basement resistivity set at $200 \Omega \mathrm{m}$. The results are shown for a model with an r.m.s misfit of unity and 23 vertical profiles are shown between -5 and $+5 \mathrm{~km}$. The results are shown on a natural logarithmic depth scale. Also shown in Fig. 12 are the 23 equivalent vertical profiles obtained from inversion of the north-south translated data along 50-RL-138. In both cases, the lack of resolution of the sedimentary section below the conductive cover is very evident. The 'noise' through the upper kilometre of the inversion of the observed data is due to inclusion of static offsets. Although differences exist with regard to cover and basement resistivities, the comparison demonstrates the similar and very low-order resolution attributes of both synthetic and observed data in this particular exploration context.

\section{Summary}

MT studies from the 1980s in two contrasting Brazilian basins have been described. In the first case, from the Clevelandia area of the Paraná basin, thick $(1200 \mathrm{~m})$ flood basalts cover a Palaeozoic sequence with hydrocarbon potential. As a result of the decreasing resistivity of the sedimentary sequence with depth, the general prognosis for maintaining a high degree of vertical resolution through to the basement is good for widebandwidth (at least 100-0.001 Hz) measurements. The bandwidth below $0.01 \mathrm{~Hz}$ is required to ensure adequate penetration of the basement.

A high degree of static distortion is displayed by the survey data. Although it might be argued that this is a common feature of many basaltcovered environments (e.g. the Columbia basalt; Shoham et al., 1992) other areas of the Paraná basin do not appear to give rise to the same degree of distortion (e.g. Stanley et al., 1985). The successful control of statics is clearly a prerequisite for adequate data modelling and interpretation.

In the second study, from the Juruá petroleum province in the Solimôes basin, a much more complex tectonic-sedimentary evolution has given rise to a complicated series of faults on a local and regional scale. Massive diabase sills also intrude the sedimentary sequence. The main problem for an MT study in the Juruá province stems from the presence of $750 \mathrm{~m}$ of highly conducting 
fluvial sediments that cover the Palaeozoic sediments. In effect, MT data appear 'blind' to the detail of the Palaeozoic sequence and associated intrusives. Even in cases of low-order vertical resolution, an examination of lateral influences on profile data is not precluded. Approximate 2D data inversion and synthetic modelling studies indicate that only highly accurate (1\%) tensor data are likely to detect the reverse faults typical of the area.

\section{Acknowledgements}

We thank Dr. F. Nepomuçenco of Petrobrás Research Center for supporting this work. We are also very grateful to Steve Constable, Catherine deGroot-Hedlin, Gaston Fischer, Bob Parker and Phil Wannamaker, whose algorithm codes have been used to model the data. We also thank the two referees and editor (Alan Jones), whose careful scrutiny much improved the manuscript. This paper is published with the approval of the Director, British Geological Survey (NERC).

\section{References}

Beamish, D. and Travassos, J.M., 1992a. The use of the $\mathrm{D}^{+}$ solution in magnetotelluric interpretation. J. Appl. Geophys., 29: 1-19.

Beamish, D. and Travassos, J.M., 1992b. A study of static shift removal from magnetotelluric data. J. Appl. Geophys., 29: 157-178.

Beamish, D. and Travassos, J.M., 1992c. Magnetotelluric imaging of basalt-covered sediments. First Break, 10: 345357.

Brazil, I.R., 1990. Solimôes Basin: oil potential and exploration perspectives-northern Brazil. Bol. Geociênc. Petrobrás, 4: 85-93.

Constable, S.C., Parker, R.L. and Constable, C.G., 1987. Occam's inversion: a practical algorithm for generating smooth models from electromagnetic sounding data. Geophysics, 52: 289-300.

deGroot-Hedlin, C., 1991. Removal of static shift in two-dimensions by regularised inversion. Geophysics, 56: 21022106.

deGroot-Hedlin, C. and Constable, C., 1990. Occam's inversion to generate smooth, two-dimensional models from magnetotelluric data. Geophysics, 55: 1613-1624.

Jones, A.G., 1988. Static shift of magnetotelluric data and its removal in a sedimentary basin environment. Geophysics, 53: $967-978$.

Milani, E.J., Kinoshita, E.M., Araûjo, L.M. and da Cruz Cunha, P.R., 1990. Paraná Basin: petroleum potential in the depocenter area. Bol. Geociênc. Petrobrás, 4: 21-34.

Oldenburg, D., 1990. Inversion of electromagnetic data: an overview of new techniques. Surv. Geophys., 11: 231-270.

Shoham, Y., Morrison, F. and Torres-Verdin, C., 1992. Electromagnetic mapping of electrical conductivity beneath the Columbia basalt. 54th Meeting, EAEG, Paris, Expanded Abstracts, EAEG, The Netherlands, pp. 418-419.

Stanley, W.D., Saad, A.R. and Ohofugi, W., 1985. Regional magnetotelluric surveys in hydrocarbon exploration, Parana Basin, Brazil. Bull. Am. Assoc. Pet, Geol., 69: $346-360$.

Wannamaker, P.E., Stodt, J.A. and Rijo, L., 1987. A stable finite element solution for two-dimensional magnetotelluric modelling. Geophys. J. R. Astron. Soc., 88: 277-296.

Weidelt, P., 1972. The inverse problem of geomagnetic induction. Z. Geophys., 38: 257-289. 